\title{
THE RELATIONSHIP BETWEEN WORKING SCHEDULE PATTERNS AND THE MARKERS OF THE METABOLIC SYNDROME: COMPARISON OF SHIFT WORKERS WITH DAY WORKERS
}

IRAJ MOHEBBI ${ }^{1}$, KAMRAN SHATERI ${ }^{2}$, and MIRHOSEIN SEYEDMOHAMMADZAD ${ }^{3}$

${ }^{1}$ Urmia University of Medical Sciences, Urmia, Iran

Occupational Medicine Department

${ }^{2}$ Urmia University of Medical Sciences, Urmia, Iran

Gastroenterology Department

${ }^{3}$ Urmia University of Medical Sciences, Urmia, Iran

Cardiology Department

\begin{abstract}
Objectives: This study examined the effect of shift work on developing the metabolic syndrome by comparing groups of exposed and unexposed Iranian drivers. Methods: We considered as night-shift drivers those drivers whose shifts included at least $15 \mathrm{~h}$ per week between 9:00 p.m. and 7:00 a.m. Daytime drivers were defined as drivers working regularly without shift work. 3039 shift work drivers were selected. These were matched with non-shift workers. The differences in baseline characteristics and the prevalence of the components of the metabolic syndrome were assessed with Student's t test, and chi-square tests. Results: We found central adiposity in $52.0 \%$ of the shift workers versus $42.6 \%$ of the day workers $(\mathrm{p}<0.0001)$. The hypertension component was not significantly related to shift work $(\mathrm{p}>0.05)$; but there were significant differences as regards other components of the metabolic syndrome $(\mathrm{p}<0.0001)$. Among the shift workers, the odds ratios of the increased FBS, low HDL-C, higher TG levels, as well as higher waist circumference were 1.992 (95\% CI: 1.697-2.337), 1.973 (95\% CI: 1.759-2.213), 1.692 (95\% CI: 1.527-1.874), and 1.460 (95\% CI: 1.320-1.616), respectively. The metabolic syndrome was more common among the shift workers (OR $=1.495$; $95 \% \mathrm{CI}: 1.349-1.657)$. Conclusion: In evaluating such results, further consideration is needed to find pathophysiological clarification; in turn, stress linked to shift work must be considered to likely have had a relevant influence on the outcome. In our opinion, shift work acts as an occupational factor for the metabolic syndrome.
\end{abstract}

Key words:

Shift work, Insulin resistance, Metabolic syndrome, Abdominal obesity, Circadian clock

This study entitled "Impact of shift work on metabolic syndrome" was supported by the Urmia University of Medical Sciences, Urmia, Iran. Received: December 7, 2011. Accepted: May 25, 2012.

Address reprint request to: I. Mohebbi, Occupational Medicine Center, Urmia University of Medical Sciences, Urmia, Iran, Post Box: 5756115111 (e-mail: mohebbi_iraj@yahoo.co.uk). 


\section{INTRODUCTION}

Human natural body rhythms are called circadian rhythms which are regulated by a "circadian clock"; located in the hypothalamus. This biological clock is synchronized by receiving the photic information from light-sensitive ganglion cells in the retina, thereby entraining individuals' physiology and behavior to the external day-night cycle [1,2]. Nearly all of the biological processes including the sleep-wake cycles, body temperature, energy metabolism, cell cycle and hormone secretion have a circadian rhythm and are controlled by this circadian clock [2-5].

Shift work disrupts the clock's function and is linked to circadian and metabolic consequences such as altered plasma lipid metabolism and adiposity [6].

A disruption of the circadian rhythm plays a key role in the pathophysiology of numerous diseases. It has become obvious that even disturbances of single aspects of these circadian rhythms may be associated with major effects [7-9]. It has been suggested that work/rest schedules resulting from shift work impair the physiological adaptation in the majority of night shift workers [1]. The sleep disorders, jetlag syndrome, and increased proneness to work-related injuries are known short-term manifestation of shift work. In the long run, medical problems may manifest as increased risks for gastrointestinal, psychoneurotic, and cardiovascular diseases [10]. Shift work-related abnormalities in circulating lipids, central obesity, and hypertension have been repeatedly reported, but evidence of elevated blood pressure or metabolic disorders in a comparison between shift workers with day workers has not been convincingly demonstrated [6,11-15]. The metabolic syndrome (MetS) or the insulin resistance syndrome constitutes a clustering of several interrelated abnormalities that increase the risk for cardiovascular events and progression to diabetes mellitus $[16,17]$. On the other hand, the risk for a cardiovascular disease among shift workers is well documented. Several population studies indicate a relationship between shift work and morbidity from cardiovascular diseases [18].
Shift work may trigger the effect of lifestyle-related risk factors on coronary heart disease [19]. The present study was designed to determine the role of shift work impact on development of MetS, by comparing groups of exposed and unexposed Iranian professional drivers.

\section{METHODS}

\section{Study population}

Iranian health surveys of professional drivers of commercial motor vehicles have looked to improve their occupational health. From 2006 to 2010, more than 22000 long-distance motor vehicle drivers were referred to our clinic. All of them reside in the West Azerbaijan Province of Iran. In this community-based study, a total of 6078 participants aged 20-60 years were included. The study protocol was approved by the Medical Ethics Committee of the Urmia University of Medical Sciences, and each participant signed a consent form.

\section{Sampling method}

For the purpose of the present study, we considered as night-shift drivers those drivers working on night or rotating shifts whose shifts included at least $15 \mathrm{~h}$ per week between 9:00 p.m. and 7:00 a.m. The daytime drivers were defined as drivers regularly working between 7:00 a.m. and 7:00 p.m. whose work was not shift-based. At baseline, a total of 4500 male shift work drivers aged 20-60 years were randomly selected among 22453 individuals. We used simple random sampling because the population was uniform and had similar characteristics in all cases, e.g. occupation and the socioeconomic level.

Then, we excluded the drivers:

- who had worked as shift workers for less than two years,

- whose driving schedule included less than 44 h/week,

- whose shift work duration included less than $15 \mathrm{~h} /$ week from 9.00 p.m. to 7.00 a.m. 
Finally, 3039 shift work drivers were selected. Thereafter, 3039 non-shift-work drivers were enrolled as a comparable group, who were matched with shift workers based on age, past smoking habit (pack-year history of smoking), period of employment as a driver, average of weekly driving in a year, and the type of the motor vehicle. Both groups were from similar socioeconomic backgrounds. The history of cigarette smoking was obtained from a questionnaire completed by each subject. The extent of smoking was quantified in pack-years, with 1 pack-years equivalent to 20 cigarettes per day for 1 year. Prior to the recruitment, all drivers had been informed about the aims of the health survey and the study. We excluded anyone who failed to provide us with an informed consent to participate in this study and applied the same inclusion and exclusion criteria to both groups.

\section{Definition of MetS}

Different organizations have proposed various criteria for the classification of MetS, and the National Cholesterol Education Program - Adult Treatment Panel III (NCEPATP III) as well as the International Diabetes Federation (IDF) criteria are used for the purpose of estimating the magnitude of MetS in the general population more widely than others. The IDF, in 2005, proposed a "consensus" definition of MetS in which waist circumference cut-off thresholds were made based on ethnicity specifics. All subjects were screened for MetS by using the IDF criteria that included the presence of central adiposity on the basis of waist circumference $\geq 94 \mathrm{~cm}$ plus two or more of the four following factors:

- elevated concentration of triglycerides (TG): $\geq 150 \mathrm{mg} / \mathrm{dl}(1.7 \mathrm{mmol} / \mathrm{l})$,

- reduced concentration of HDL cholesterol: $<40 \mathrm{mg} / \mathrm{dl}(1.03 \mathrm{mmol} / \mathrm{l})$,

- elevated blood pressure: systolic blood pressure (SBP) $\geq 130 \mathrm{mmHg}$ or diastolic blood pressure (DBP) $\geq 85 \mathrm{mmHg}$,
- elevated fasting plasma glucose (FBS) concentration $\geq 100 \mathrm{mg} / \mathrm{dl}(5.6 \mathrm{mmol} / \mathrm{l})[20]$.

\section{Medical history and clinical examination}

According to the national protocol, demographic data including: age, shift work, smoking habits, duration of driving experience as the main job, type of motor vehicle, and the socioeconomic status of workers were collected using a standardized questionnaire. Waist circumference was measured at the level of the umbilicus in the standing position of the subjects. The subjects' blood pressure was measured after a five-minute rest, using a standard mercury sphygmomanometer with a suitable cuff calibrated by the Iranian Institute of Standards and Industrial Researches. Two consecutive diastolic and systolic blood pressures were recorded on the right arm. If the two-measurement difference exceeded 5\%, blood pressure was measured for the third time. There were at least 30 -second intervals between the measurements; the average of the two closest readings was considered as the subject's blood pressure.

\section{Serum lipid and glucose analysis}

Baseline blood samples were drawn into vacutainer tubes between 7:00 a.m. and 9:00 a.m. All the participants had fasted for $\geq 10 \mathrm{~h}$. FBS and lipids were quantified at the time of specimen collection in the central laboratory of UMSU, a reference laboratory that had served Urmia residents for decades. Blood glucose and lipids, including TG and HDL cholesterol, were analyzed using a BT-3000 auto-analyzer (Biotecnica, Rome, Italy). The HDL-C and TG were assayed using enzymatic tests with commercially available kits (Pars Azmoon Inc., Iran). All samples were analyzed when the daily internal quality controls matched the acceptable criteria.

\section{Statistical analysis}

The characteristics of each group were summarized by means, standard deviations and percentages, subdivided 
into four categories by age, and three body mass index $\left(\mathrm{BMI}=\right.$ weight $/$ height $\left.^{2}\right)$ categories. The differences in baseline characteristics and the prevalence of components of MetS between the exposed and the non-exposed groups were assessed with Student's t test, and chi-square tests. A potential difference was considered significant on the basis of $\mathrm{p}$, when it was lower than 0.05 .

\section{RESULTS}

Among the components of Mets, the mean FBS, TG, and waist circumference in the group of shift workers were higher than in the group of day workers. These variables differed significantly between the two groups. The shift workers group had significantly lower HDL. BMI differed significantly between the two groups, but the mean systolic and also diastolic BPs showed no significant differences between the two groups (Table 1). The frequency of overweight (BMI: 25-29.9) was the same in shift workers and day workers [1275 (42.0\%) vs. 1279 (42.1\%)]. In shift workers and day workers, respectively, obesity (BMI $\geq 30)$ was observed in $647(21.3 \%)$ and 395 (13.0\%) participants. The prevalence of the metabolic syndrome components in both groups is reported in Table 2.

Central adiposity was the most common metabolic abnormality in both groups. The chi-square test revealed the central

Table 1. Baseline characteristics of the study population according to shift work

\begin{tabular}{lccccc}
\hline \multirow{2}{*}{ Variable } & \multicolumn{2}{c}{ Shift workers } & \multicolumn{2}{c}{ Day workers } & \multirow{2}{*}{$\mathrm{p}$} \\
\cline { 2 - 4 } & $\mathrm{M}$ & $\mathrm{SD}$ & $\mathrm{M}$ & $\mathrm{SD}$ & \\
\hline Systolic BP (mmHg) & 123.71 & 14.729 & 123.57 & 14.428 & NS $(0.721)$ \\
Diastolic BP (mmHg) & 77.4788 & 10.34743 & 77.7680 & 10.15777 & NS $(0.272)$ \\
TG (mg/dl) & 182.88 & 143.992 & 152.13 & 101.456 & $<0.001$ \\
HDL (mg/dl) & 44.13 & 9.895 & 46.26 & 9.279 & $<0.001$ \\
FBS (mg/dl) & 91.58 & 21.084 & 88.90 & 15.533 & $<0.001$ \\
Waist circumference (cm) & 93.6018 & 11.94843 & 90.5747 & 10.75563 & $<0.001$ \\
BMI & 26.6760 & 4.09526 & 25.7145 & 3.76029 & $<0.001$ \\
\hline
\end{tabular}

BP - blood pressure, TG - triglyceride, HDL - high density lipoprotein, FBS - fasting blood sugar, BMI - Body Mass Index, M - mean, SD - standard deviation, NS - not significant.

Table 2. Prevalence of the components of the metabolic syndrome (MetS)

\begin{tabular}{lccccc}
\hline \multicolumn{1}{c}{ Variable } & $\begin{array}{c}\text { Shift workers } \\
\mathrm{n}(\%)\end{array}$ & $\begin{array}{c}\text { Day workers } \\
\mathrm{n}(\%)\end{array}$ & $\mathrm{p}$ & Odds ratio & 95\% CI \\
\hline $\mathrm{FBS} \geq 100 \mathrm{mg} / \mathrm{dl}$ & $479(15.8)$ & $261(8.6)$ & $<0.0001$ & 1.992 & $1.697-2.337$ \\
$\mathrm{HDL}<40 \mathrm{mg} / \mathrm{dl}$ & $1052(34.6)$ & $643(21.2)$ & $<0.0001$ & 1.973 & $1.759-2.213$ \\
$\mathrm{TG} \geq 150 \mathrm{mg} / \mathrm{dl}$ & $1499(49.3)$ & $1110(36.5)$ & $<0.0001$ & 1.692 & $1.527-1.874$ \\
Waist circumference $\geq 94 \mathrm{~cm}$ & $1580(52.0)$ & $1294(42.6)$ & $<0.0001$ & 1.460 & $1.320-1.616$ \\
Systolic BP $\geq 130$ or diastolic BP & $1089(35.8)$ & $1138(37.4)$ & $\mathrm{NS}(0.101)$ & 0.933 & $0.840-1.036$ \\
$\quad$ & & & & \\
MetS & $135(\mathrm{mmHg})$ & & & & \\
\hline
\end{tabular}

Abbreviations as in Table 1. 
adiposity in $52.0 \%$ of the shift workers versus $42.6 \%$ of the day workers $(p<0.0001)$. The hypertension component was not significantly related to shift work $(p>0.05)$; whereas there were significantly different frequencies of other components of MetS as well as BMI which are not part of the metabolic syndrome $(p<0.0001)$. Among the shift workers, the odds ratio of the increased FBS, low HDL-C, higher TG levels, as well as higher waist circumference were 1.992 (95\% CI: 1.697-2.337), 1.973 (95\% CI: 1.759-2.213), 1.692 (95\% CI: 1.527-1.874) and 1.460 (95\% CI: 1.320-1.616), respectively. Among the shift workers, MetS was more common than in the group of the day workers (odds ratio (OR): 1.495; 95\% CI: 1.349-1.657).

In the shift workers and day workers, respectively, MetS increased from $25.8 \% \%$ and $24.5 \%$ within the $20-29$ yearold group to $62.4 \%$ and $46.8 \%$ in the subjects of more than 50 years of age, as shown in Table 3.

The prevalence of two or more abnormalities of MetS without the obesity component was higher among the shift workers, whereas having one abnormality was manifested in the youngest age group of the day workers (Table 4).
Shift work increases the prevalence of MetS (OR $=1.495$; 95\% CI: 1.349-1.657). There was a significant age-related increase in the prevalence of MetS in both the shift and day workers groups. Our findings showed that it was more prevalent the among the shift than day workers in all age groups.

\section{DISCUSSION}

After adjusting the results for objective confounders, the present study showed that the shift work pattern was associated with a higher prevalence of MetS. Our findings revealed that some components included in MetS, such as higher waist circumference, increased fasting blood glucose, and higher triglycerides blood levels as well as low HDL-C, were more common among the shift drivers in comparison to the day workers. On the other hand, we found no significant association concerning the blood pressure component between the shift workers and day ones.

The work-related factors of professional driving may affect the lipid metabolism and obesity due to various

Table 3. Prevalence of the metabolic syndrome (MetS) stratified by age groups and work category

\begin{tabular}{lcccccc}
\hline \multirow{2}{*}{ Working category } & MetS & \multicolumn{5}{c}{ Age groups (years) / Year } \\
\cline { 3 - 6 } & & $20-29$ & $30-39$ & $40-49$ & $>50$ & total \\
\cline { 3 - 6 } & yes & $160(25.8)$ & $415(40.4)$ & $481(55.5)$ & $328(62.4)$ & $1384(45.5)$ \\
\multirow{2}{*}{ Dhift workers workers } & no & $461(74.2)$ & $611(59.6)$ & $385(44.5)$ & $198(37.6)$ & $1655(54.5)$ \\
& yes & $152(24.5)$ & $369(36.0)$ & $323(37.3)$ & $246(46.8)$ & $1090(35.9)$ \\
& no & $469(75.5)$ & $657(64.0)$ & $543(62.7)$ & $280(53.2)$ & $1949(64.1)$ \\
\hline
\end{tabular}

Table 4. Prevalence of abnormalities of the metabolic syndrome (MetS), except the obesity component, stratified by work category

\begin{tabular}{lrrrrrr}
\hline \multirow{2}{*}{ Work category } & \multicolumn{7}{c}{ Frequency of components } \\
& \multicolumn{7}{c}{ no $(\%)$} \\
\cline { 2 - 7 } & $707(23.3)$ & 1.00 & 2.00 & 3.00 & 4.00 & total \\
\hline Shift workers & $1039(34.2)$ & $857(28.2)$ & $378(12.4)$ & $58(1.9)$ & $3039(100.0)$ \\
Day workers & $672(22.1)$ & $1626(53.5)$ & $712(23.4)$ & $14(0.5)$ & $15(0.5)$ & $3039(100.0)$ \\
Total & $1379(22.7)$ & $2665(43.8)$ & $1569(25.8)$ & $392(6.4)$ & $73(1.2)$ & $6078(100.0)$ \\
\hline
\end{tabular}


harmful stressors including: the socioeconomic status, job and position, continuous tension caused by driving, lack of exercise, changes experienced in life due to an irregular work schedule [21-23]. Our findings are similar to those of other studies [24-26] that reported a higher tendency towards overweight or central obesity in the shift workers than in the day workers.

Increased blood pressure as the key component of MetS is the most widely studied factor in relation to the syndrome [27]. The relationship between elevated blood pressure and shift work is controversial. Although some studies have identified a trend towards higher blood pressure among shift workers [14], the present study and the results of other studies [26,28,29] showed no statistically significant differences in both the mean systolic and diastolic blood pressures.

In some studies, there was no difference in the triglyceride levels between the shift and day workers [12,26], whereas several population studies have shown that shift work could lead to a high prevalence of the elevated triglyceride levels concentrations $[13,6]$. It has been suggested that shift work is associated with an increase in the triglyceride levels independent of the dietary intake [30]. In the present study, the same was true for higher triglyceride levels among the shift workers. Karlsson et al. found a significant association between shift work and obesity, and also the abnormalities in circulating lipids such as low HDL-cholesterol and high triglyceride levels, indicating an association between shift work and the metabolic syndrome. Based on their findings, the risk of low HDL-cholesterol was doubled among the shift workers [6].

Although the abnormalities in circulating lipids and abdominal obesity have been repeatedly reported in shift workers, there are few studies reporting impaired glucose metabolism in relation to shift work. In the present study, higher FBS in shift workers was consistent with a 14-year cohort study of 7104 male Japanese workers which revealed that shift work was an independent risk factor for impaired glucose metabolism [31].

Although the primary cause of the weight gain leading to MetS is attributed to increased caloric intake and decreased energy expenditure, some studies point out that the overall food content or caloric intake are not related to shift work [32].

Epidemiological studies have documented that abdominal obesity and its metabolic comorbidities are the consequence of a chronic maladaptation to environmental stress factors [33], which is also is agreement with some epidemiological studies showing an association of MetS with the job stress $[34,35]$. The hallmark of the stress response is increased cortisol secretion by the hyperactivation of the hypothalamic-pituitary-adrenocortical (HPA) axis [36]; which can cause insulin sensitivity to decrease in the muscles [37], inhibit glucose uptake by the peripheral tissues and also lead to an increase in both lipolysis and gluconeogenesis [38].

Although we cannot define this condition precisely as a direct effect of shift work, it should be noted that visceral obesity plays the key role in the development of insulin resistance [39], and insulin levels are associated with higher BMI and also higher visceral obesity which alters glucose metabolism mediated by decreasing insulin sensitivity [24]. Shift work increases obesity [6], so the difference in the blood glucose levels between the shift workers and the control group may be indirectly caused by shift work. In addition, the measurement of BMI could be useful for identifying persons at increased risk of developing MetS among the shift workers. The same may be true for the disruption of the circadian rhythm which may "per se" play the main role in inducing metabolic disturbances of MetS [11,40]. It is worth noting that some investigators have reported that metabolic changes have been observed to occur independently of poor diet and physical inactivity. Branth et al. concluded that despite regular exercise and a proper diet, subjects under 
prolonged stress developed metabolic alterations including distinctive central obesity, biochemical changes and slight hypertension towards MetS [41]. As an opposite reason as in the earlier studies $[6,12,24,41]$, it seems possible that shift work is responsible for both the elevated TG levels and higher FBS. In turn; stress linked to shift work causes insulin sensitivity to decrease and impaired FBS.

In the present study, we did not examine dietary habits and daily exercise with objective methods; so, no clearcut conclusion could be drawn with regard to this aspect. Professional driving is associated with substantial changes in lifestyle habits. Physical inactivity is common in Iranian long-distance drivers and, also, an interview conducted with some subjects by a dietitian clearly showed that the only option they have is to have their meals in restaurants. Both shift and day workers have similar limited options as regards their meals. Most restaurants use high saturated fat for daily cooking and the usual meals consumed in these restaurants are poor in fibers (vegetables and fruits), rich in animal proteins (beef, sheep, veal), foods with high glycemic index (rice, white bread), and saturated fat (cheese, eggs) that are well known to induce an increase of the body fat in working individuals [42].

The present study supports the effect of shift work on MetS in line with those from other authors. In evaluating such results, further consideration is needed to find pathophysiological clarifications; in turn, stress linked to shift work, must be considered as having a relevant influence on MetS.

\section{CONCLUSION}

In our opinion, shift work acts as an occupational factor for MetS. All professional drivers of commercial motor vehicles, particularly shift workers, should be carefully evaluated by occupational physicians for MetS in order to promote preventive and corrective actions.

\section{ACKNOWLEDGEMENTS}

The authors are grateful to Dr Mohammadreza Aghassi, Dr Magsoud Matinkhah, Dr Mahsa Shekari, Dr Shadi Sehat, Mr Farzad Bahmannejadin, Mr Farman Noorozi, and Mr Mostafa Saadat for their assistance.

\section{REFRENCE}

1. Szosland D. Shift work and metabolic syndrome, diabetes mellitus and ischaemic heart disease. Int J Occup Med Environ Health 2010;23:287-91.

2. Golombek DA, Rosenstein RE. Physiology of circadian entrainment. Physiol Rev 2010;90:1063-102.

3. Rana S, Mahmood S. Circadian rhythm and its role in malignancy. J Circadian Rhythm 2010;8:3. DOI10.1186/17403391-8-3.

4. Tsai JY, Kienesberger PC, Pulinilkunnil T, Sailors MH, Durgan DJ, Villegas-Montoya C, et al. Direct regulation of myocardial triglyceride metabolism by the cardiomyocyte circadian clock. J Biol Chem 2010;285:2918-29.

5. Kohyama J. A newly proposed disease condition produced by light exposure during night: Asynchronization. Brain Dev 2009;31:255-73.

6. Karlsson B, Knutsson A, Lindahl B, Alfredsson L. Metabolic disturbances in male workers with rotating three-shift work. Results of the WOLF study. Int Arch Occup Environ Health 2003;76:424-30.

7. Kogi K. International research needs for improving sleep and health of workers. Ind Health 2005;43:71-9.

8. Bray MS, Young ME. Diurnal variations in myocardial metabolism. Cardiovasc Res 2008;79:228-37.

9. Keller M, Mazuch J, Abraham U, Eom GD, Herzog ED, Volk HD, et al. A circadian clock in macrophages controls inflammatory immune responses. Proc Natl Acad Sci USA 2009;106:21407-12.

10. Eliasson B, Attvall S, Taskinen MR, Smith U. The insulin resistance syndrome in smokers is related to smoking habits. Arterioscler Thromb 1994;14:1946-50. 
11. De Bacquer D, Van Risseghem M, Clays E, Kittel F, De Backer G, Braeckman L. Rotating shift work and the metabolic syndrome: a prospective study. Int J Epidemiol 2009;38:848-54.

12. Nakamura K, Shimai S, Kikuchi S, Tominaga K, Takahashi H, Tanaka M, et al. Shift work and risk factors for coronary heart disease in Japanese blue-collar workers: serum lipids and anthropometric characteristics. Occup Med 1997;47:142-6.

13. Sookoian S, Gemma C, Fernández Gianotti T, Burgueño A, Alvarez A, González CD, et al. Effects of rotating shift work on biomarkers of metabolic syndrome and inflammation. J Intern Med 2007;261:285-92.

14. Peter R, Alfredsson I, Knutsson A, Siegrist J, Westerholm P. Dose a stressful psychosocial work environment mediate the effects of shiftwork on cardiovascular risk factors? Scand J Work Environ Health 1999;25:376-81.

15. Karlsson B. Commentary: metabolic syndrome as a result of shift work exposure? Int J Epidemiol 2009;38:854-5.

16. Isomaa B, Almgren P, Tuomi T, Forsen B, Lahti K, Nissen M, et al. Cardiovascular morbidity and mortality associated with the metabolic syndrome. Diabetes Care 2001;24:683-9.

17. Malik S, Wong ND, Franklin SS, Kamath TV, L'Italien GJ, Pio JR, et al. Impact of the metabolic syndrome on mortality from coronary heart disease, cardiovascular disease, and all causes in the United States adults. Circulation 2004;110: 1245-50.

18. Thomas C, Power C. Shift work and risk factors for cardiovascular disease: a study at age 45 years in the 1958 British birth cohort. Eur J Epidemiol 2010;25:305-14.

19. Harma MI, Ilmarinen JE. Towards the 24-hour society-new approaches for aging shift workers? Scand J Work Environ 1999;25:610-5.

20. International Diabetes Federation. The IDF consensus worldwide definition of the metabolic syndrome [cited 2005 Sept 2]. Available from URL: http://www.idf.org/webdata/ docs/Metabolic_syndrome_definition.pdf.

21. Langenberg C, Hardy R, Kuh D, Brunner E, Wadsworth M. Central and total obesity in middle aged men and women in relation to lifetime socioeconomic status: evidence from a national birth cohort. J Epidemiol Community Health 2003;57: 816-22.

22. Goodman E, Slap GB, Huang B. The public health impact of socioeconomic status on adolescent depression and obesity. Am J Public Health 2003;93:1844-50.

23. Wellman NS, Friedberg B. Causes and consequences of adult obesity: health, social and economic impacts in the United States. Asia Pac J Clin Nutr 2002;11:S705-9.

24. Di Lorenzo L, De Pergola G, Zocchetti C, LAbbate N, Basso A, Pannacciulli N, et al. Effect of shift work on body mass index: Results of a study performed in 319 glucosetolerant men working in a Southern Italian industry. Int J Obesity 2003;27:1353-8.

25. Ha M, Park J. Shiftwork and metabolic risk factors of cardiovascular diseases. J Occup Health 2005;47:89-95.

26. Karlsson B, Knutsson A, Lindahl B. Is there an association between shift work and having a metabolic syndrome? Results from a population based study of 27,485 people. Occup Environ Med 2001;58:747-52.

27. Timar O, Sestier F, Levy E. Metabolic syndrome X: A review. Can J Cardiol 2000;16:779-89.

28. Knutsson A, Akerstedt T, Jonsson BG. Prevalence of risk factors for coronary artery disease among day and shift workers. Scand J Work Environ Health 1988;14:317-21.

29. Sfreddo C, Fuchs SC, Merlo AR, Fuchs FD. Shift work is not associated with high blood pressure or prevalence of hypertension. PLoS ONE 2010;5(12):e15250. DOI:10.1371/journal. pone. 0015250 .

30. Romon M, Nuttens MC, Fievet C, Pot P, Bard JM, Furon D, et al. Increased triglyceride levels in shift workers. Am J Med 1992;93:259-62.

31. Suwazono Y, Dochi M, Oishi M, Tanaka K, Kobayashi E, Sakata K. Shiftwork and impaired glucose metabolism: a14-year cohort study on7104 male workers. Chronobiol Int 2009;26:926-41.

32. Pasqua IC, Moreno CR. The nutritional status and eating habits of shift workers: a chronobiological approach. Chronobiol Int 2004;2:949-60. 
33. Lallukka T, Laaskonen M, Matikainen P, Sarlio-Lahteenkrva S, Lahelma E. Psychosocial working conditions and weight gain among employees. Int J Obes 2005;29:909-19.

34. Kang MG, Koh SB, Cha BS, Park JK, Woo JM, Chang SJ. Association between job stress on heart rate variability and metabolic syndrome in shipyard male workers. Yonsei Med J 2004:45:838-46.

35. Chandola T, Brunner E, Marmot M. Chronic stress at work and the metabolic syndrome. Br Med J 2006;332:521-5.

36. McEwen BS. Physiology and neurobiology of stress and adaptation: central role of the brain. Physiol Rev 2007;87:873-904.

37. Bjorntorp P, Rosmond R. Hypothalamic origin of the metabolic syndrome X. Ann NY Acad Sci 1999;892:297-307.

38. Bjorntorp P. The regulation of adipose tissue distribution in humans. Int J Obes 1996;20:291-302.
39. Prabhakaran D, Anand SS. The metabolic syndrome: an emerging risk state for cardiovascular disease. Vasc Med 2004;9:55-68.

40. Biggi N, Consonni D, Galluzzo V, Sogliani M, Costa G. Metabolic syndrome in permanent night workers. Chronobiol Int 2008;25:443-54.

41. Branth S, Ronquist G, Stridsberg M, Hambraeus L, Kindgren E, Olsson R, et al. Development of abdominal fat and incipient metabolic syndrome in young healthy men exposed to long-term stress. Nutr Metab Cardiovasc Dis 2007;17:427-35.

42. French SA, Jeffery RW, Forster JL, McGovern PG, Kelder SH, Baxter JE. Predictors of weight change over two years among a population of working adults: the Healthy Worker Project. Int J Obes Relat Metab Disord 1994;18: $145-54$.

This work is available in Open Access model and licensed under a Creative Commons Attribution-NonCommercial 3.0 Poland License - http://creativecommons.org/ licenses/by-nc/3.0/pl/deed.en. 